\title{
A democratização da gestão da política de assistência social: fragmentos de um estudo
}

\author{
Márcia Pastor \\ Universidade Estadual de Londrina (UEL)
}

\section{A democratização da gestão da política de assistência social: fragmentos de um estudo}

Resumo: Este artigo discute o acesso à informação como um dos aspectos constituintes da gestão democrática a partir da experiência da política de assistência social em Londrina, Paraná, no período compreendido entre 2001 e 2004. Traz apontamentos sobre democratização e gestão e examina as visões dos sujeitos envolvidos na efetivação desta política pública. Os dados coletados através de pesquisa documental e de entrevistas semi-estruturadas com gestores, conselheiros municipais, dirigentes de entidades sociais, assistentes sociais e usuários, que compuseram a tese de doutorado da autora, revelaram o entendimento da democratização como viabilização do acesso aos direitos sociais e à participação. $\mathrm{O}$ acesso às informações evidenciou-se como elemento qualificador da gestão democrática e como princípio incorporado na prática dos gestores e profissionais.

Palavras-chave: assistência social, democratização, gestão, acesso à informação.

\section{The Democratization of Social Assistance Policy Administration: Fragments of a Study}

Abstract: This article discusses access to information as one of the essential elements of democratic administration based on the experience of the social assistance policy in Londrina, Paraná, from 2001 - 2004. It discusses democratization and management and examines the views of the actors involved in the enactment of this public policy. The data collected in the study of documents and semistructured interviews with administrators, municipal council members, directors of social entities, social workers and users, was used for the author's doctoral thesis. They reveal the understanding of democratization as making viable access to social rights and participation. The access to information proved to be a qualifying element in democratic management and a principle incorporated in the practice of managers and professionals.

Key words: social work, democratization, administration, access to information. 


\section{Introdução}

A implementação da gestão democrática da assistência social revela que é no cotidiano que se constrói, com avanços e com limites, uma política pública afiançadora de direitos, especialmente numa conjuntura que assiste à destruição dos padrões de proteção embasados no trabalho e da tentativa de destituição dos direitos sociais.

Por isso, falar em gestão democrática é falar também da busca pela efetivação dos direitos sociais, particularmente para os setores sociais excluídos e que se encontram em condições mais vulneráveis.

\section{A democratização e a gestão: apontamentos iniciais}

Ao olharmos as últimas três décadas, podemos testemunhar o quanto a sociedade brasileira avançou em termos de resgate dos direitos políticos e de consagração dos direitos sociais: do regime de exceção ao pluripartidarismo; do Colégio Eleitoral às eleições diretas para presidente; das reivindicações e emendas populares à garantia dos direitos sociais assegurados pela Constituição Federal de 1988.

Analisando esse período, Chauí (2004, p. 1) assim se refere:

A Constituinte que tivemos nos anos oitenta foi essencial para o processo democrático, fez parte dessas lutas políticas, sociais e democráticas, mas, no caso, significa também a ampliação da noção de democracia, na qual a democracia não é confundida apenas como um tipo de governo, mas é pensada como a presença de direitos sociais, econômicos e culturais.

Ao reconhecer que os direitos sociais são legitimados e que devem ser garantidos primordialmente através da ação do Estado, diversos segmentos sociais investiram tanto na cobrança como na proposição de ações a serem implementadas pelo poder público, reivindicando também a ampliação da participação em suas várias instâncias.

A década de 1990 foi marcada pela elaboração das leis complementares à Constituição, dentre as quais podemos destacar o Estatuto da Criança e do Adolescente (ECA-Lei 8.069/1990), a Lei Orgânica da Saúde (Leis 8.080/1990 e 8.142/1990) e a Lei Orgânica da Assistência Social (LOAS-Lei 8.742/1993). Dentre outros atributos, tais leis indicaram a descentralização político-administrativa e a participação da população como diretrizes a serem adotadas para a execução das políticas sociais (BRASIL, 2007).

Há que se considerar que a luta pela efetivação dos direitos inscritos na Constituição continuou sen- do protagonizada pelas classes dominadas e por setores progressistas. Foi num período marcado pela imposição das diretrizes neoliberais que, dentre outras ações, procurou desqualificar movimentos sindicais e sociais rotulando-os como representantes do atraso e prejudiciais à democracia; promoveu a destituição dos direitos trabalhistas; impôs medidas provisórias, restringindo direitos sociais e previdenciários e reduzindo o já precário sistema de proteção social.

Sob a égide de um regime político democrático, diversas experiências provocaram a revisão e a re-significação de conceitos e de estratégias que, no limiar do século 21 , dessem conta de explicar as mutações de uma sociedade cuja riqueza crescia velozmente, mas que, simultaneamente, alijava deste progresso um contingente crescente da população brasileira.

Autor do célebre artigo A democracia como valor universal, publicado em plena vigência da ditadura militar (1979), Coutinho polemizava, dentro do campo da esquerda, o reducionismo do entendimento da democracia como uma etapa de transição do capitalismo para o socialismo.

Transcorridos mais de vinte anos da publicação de tal artigo, o autor propôs a rediscussão do tema, ressaltando a democracia como um processo histórico:

Talvez hoje eu mudasse o título do meu artigo para 'A democratização como valor universal', porque a democracia é necessariamente alguma coisa que se aprofunda e que combina indissoluvelmente reformas políticas com reformas econômicas e sociais. A democracia é soberania popular, é construção de uma comunidade participativa, é igualdade (COUTINHO, 2000, p. 129).

Já Oliveira (2000) relembra que nos anos 1980 a democracia foi saudada como uma importante conquista social e trouxe consigo uma grande expectativa de governabilidade. Logo em seguida, porém, o que se assistiu foi uma série de ações concretas, pautadas nos ditames neoliberais, visando a destruição dos direitos coletivos.

Embora a democracia estivesse constantemente presente nos discursos oficiais, processou-se um movimento de 'desqualificação da política', de supressão dos dissensos, de 'destituição da fala' e de desmoralização das demandas sociais e das alternativas apresentadas ao modelo imposto, rotuladas como 'arcaicas'. Tentou-se criar uma falsa consciência sobre a 'desnecessidade do público', repertório obviamente necessário para os processos de privatização que marcaram a década de 1990.

O que a destruição do público opera em relação às classes dominadas [...] é a destruição de sua política, o roubo da fala, sua exclusão do discurso reivindicativo e, no limite, sua destruição como clas- 
se; seu retrocesso ao estado de mercadoria, que é o objetivo neoliberal (OLIVEIRA, 2000, p. 79).

O que se viu, portanto, foi o empenho em infundir uma democracia esvaziada de sua substância, ao mesmo tempo em que diversos atores sociais buscavam implementar a cidadania e a consolidação dos espaços democráticos, ilustrando assim o caráter dinâmico e contraditório do processo democrático, pois:

Só pode haver democracia para as grandes massas da população se elas forem capazes de se organizar, de expressar seus anseios e de obter efetivamente conquistas sociais, culturais e políticas no quadro de uma institucionalidade em permanente expansão. Assim, a democratização é um valor universal sobretudo porque é um permanente desafio. Nunca poderemos chegar a um ponto que nos permita dizer que a democracia está acabada. A democracia é um processo que devemos conceber como em permanente construção (COUTINHO, 2000, p. 131).

Na década de 1990, uma das características do novo rearranjo político proposto pela recém-aprovada Carta Magna pode ser verificado na descentralização das políticas sociais. Apesar das expectativas iniciais, a transferência de responsabilidades para as instâncias locais constituiu-se, em grande parte, em mais uma forma de escamotear o enfretamento à pobreza, mas também abriu possibilidades para iniciativas mais ousadas no campo da gestão participativa. Tal ambigüidade também norteou a implementação da política de assistência social, conforme se discutirá mais adiante.

A descentralização político-administrativa teve dentre seus propósitos a luta contra a subordinação dos municípios ao governo central. Sua inclusão nos ditames legais contou com o apoio de amplos segmentos da sociedade. Defendia-se que a esfera municipal estaria mais próxima dos problemas da população e que possibilitaria o conhecimento mais adequado da sua própria realidade. Conseqüientemente, poderia gerar proposições e ações mais condizentes ao atendimento das demandas específicas de cada localidade.

Verificou-se que parte considerável dos problemas enfrentados pelos municípios (os efeitos da urbanização não planejada e da desindustrialização, por exemplo) não podia ser solucionada somente na sua esfera de governo, pois a maioria não tinha poder (político e econômico) para interferir nos fatores causadores do aumento da pobreza, originados pelo próprio modo de produção e de reprodução social capitalista.

Como contraponto, a existência de uma esfera de governo local pode ser mais permeável à atuação da sociedade civil organizada, propiciando condições para uma gestão mais democrática e participativa e voltada aos interesses sociais. Se, por um lado, o âmbito municipal apresenta limitações para superar a pobreza, por outro, pode ter condições de atenuar os índices de desigualdades locais, propondo alternativas de enfrentamento às diversas manifestações da questão social e que possam efetivar os direitos sociais.

Há que se ponderar, todavia, que esta experiência acontecia ao mesmo tempo em que se vivenciava, no cenário nacional, a adoção da programática neoliberal com o conseqüente corte nos gastos públicos destinados às políticas sociais.

A diretriz descentralizadora aponta outro aspecto que contribui na abordagem desta reflexão: consiste na identificação da descentralização com a democratização da gestão, propondo a participação da comunidade nos processos de elaboração e de deliberação nas políticas sociais.

Dentre as aberturas trazidas pelo novo ordenamento constitucional, a descentralização vem se somar à proposição da atuação autônoma dos municípios. Por outro lado, tais aberturas não foram acompanhadas dos devidos recursos para a concretização destas alternativas. Ao contrário, com a crise fiscal do Estado, foram os municípios que acabaram arcando com o ônus da redução dos gastos sociais. A crise financeira também foi utilizada para justificar o desenvolvimento de práticas participativas no âmbito municipal, mas muitas vezes com o propósito de viabilizarem políticas e serviços públicos de forma mais barata.

Partindo do discurso de que o Estado, por si só, não tem sido capaz de promover o desenvolvimento social e econômico, deixando grandes parcelas da população excluídas do atendimento às necessidades humanas elementares, um forte apelo foi feito à sociedade civil: que ela também assumisse a tarefa de responder aos problemas decorrentes das desigualdades sociais através da livre iniciativa e da mobilização de grupos de pessoas, de instituições, de organizações não-governamentais e de empresas.

Yazbek (2000) alerta que, por trás do deslocamento da esfera pública para a esfera privada, situa- 
se a despolitização da própria questão social e a ameaça de ver frustrada a universalização e a efetivação de direitos sociais legalmente adquiridos, que podem vir a ser substituídos "pelo dever moral de atender à pobreza."

A interpretação neoliberal sobre o papel do Estado estimulou diversos debates, dentre os quais se situa a proposta de reforma do Estado, que partia do pressuposto da necessidade da administração pública incorporar procedimentos gerenciais visando a eficiência de suas ações.

De acordo com Bento (2003, p. 152),

[...] o plano de reconstrução do Estado vai além de um imperativo de eficiência. Trata-se também de reconstruir a esfera pública, de fortalecer a sociedade civil, sua capacidade de autogestão; ao mesmo tempo, de superar o insulamento burocrático, de combater a falta de responsabilidade política e administrativa pela má formulação ou implementação de estratégias, e de prevenir a captura dos governos por interesses corporativos e a privatização do espaço público.

As discussões a respeito da gestão emergem na segunda metade da década de 1990. Dentre as especificidades da gestão pública, Nogueira (1998, p. 202) situa que

[...] a gerência pública não se separa da questão da democracia e do aperfeiçoamento dos mecanismos democráticos, devendo-se dedicar a estimular a participação dos cidadãos e a fazer com que os atos do poder sejam transparentes e estejam submetidos a um efetivo controle social.

A perspectiva que norteia este estudo pauta-se na compreensão da gestão exercida no terreno dos direitos e desenvolvida de forma a contar com a participação de profissionais, conselheiros e usuários, dentre outros, não apenas na discussão como também na deliberação sobre ações a serem adotadas.

É necessário considerar a democratização da gestão como o espaço onde se negocia o consenso entre os diversos atores sociais, geralmente motivados por seus interesses específicos. Compreende-se, pois, que o exercício da gestão democrática seja eivado de conflitos e contradições, mas também abre uma possibilidade de publicizar os interesses em disputa.

\section{Uma expressão da democratização da gestão da assistência social no município de Londrina: o acesso à informação}

Ao discutir a gestão da política de assistência social implementada a partir da década de 1990 do século 20 , faz-se necessário pontuar, ainda que breve- mente, o contexto histórico no qual se desenvolve esta política pública no país.

As contradições imanentes às políticas sociais no capitalismo assumem contornos mais nítidos quando se referem à assistência social, visto que esta se caracteriza pela tensão permanente entre responder às demandas mais agudas decorrentes da questão social, ao mesmo tempo em que questiona as condições que geram estas mesmas demandas. Ao atender as carências das camadas empobrecidas, contribui para a reprodução do próprio modelo capitalista que cria essa pobreza, estruturado na apropriação privada da riqueza socialmente produzida.

As diretrizes e os princípios estabelecidos pela LOAS, entretanto, surgem na contramão da conjuntura dos anos 1990, onde se observou a adoção das medidas neoliberais que ditavam ao Estado a redução dos gastos nas áreas sociais.

Nas palavras de Raichelis (1998), tal situação demonstrava um dos grandes desafios para a política de assistência social: estruturar-se como 'política' e consolidar-se como 'pública'.

De fato, a implantação da assistência social não só como uma política pública, mas também com a perspectiva democrática em sua gestão, mereceu atenção em diversas administrações municipais, como no estudo de caso do município de Londrina, no estado do Paraná, referente ao período compreendido entre os anos 2001 a 2004 (PASTOR, 2006).

A preocupação com a construção dessa política fez-se notar desde a criação do órgão gestor municipal, em 1993. Porém, a estruturação de programas e serviços com orçamento e equipe próprios, obtidos neste mandato (1993-1996), não teve continuidade na administração seguinte.

As experiências da segunda gestão (1997-2000) demonstraram, mais uma vez, o quanto a área da assistência é vulnerável às determinações políticas no âmbito local, além de susceptível às macrodeterminações políticas e econômicas, especialmente na conjuntura em que vivíamos na transição do século 20 para o 21. Por sua vez, o período referente aos anos 2001 a 2004 - abordado no estudo citado - trouxe avanços consideráveis quanto à democratização da gestão.

Mais uma vez, cabe ressaltar que o processo de construção da gestão da assistência social no âmbito municipal insere-se num contexto maior no qual se constata "a existência de uma cultura política que se mantém ao longo do autoritarismo, sugerindo um entendimento da democratização como um processo mais longo de transformação da cultura política e das relações Estado-sociedade" (AVRITZER, 1995, p.109-110). Ter esta compreensão sobre o movimento histórico é essencial para balizar as melhorias concretizadas, ainda que limitadas pelos marcos estruturais da ordem capitalista. 
Na pesquisa desenvolvida, levantou-se com um conjunto de atores (uma gestora municipal, duas assessoras, duas assistentes sociais, dois conselheiros municipais, três dirigentes de entidades assistenciais e três usuários) suas visões sobre a gestão da política municipal de assistência social. Os dados coletados revelaram o entendimento da democratização como viabilização do acesso aos direitos sociais e à participação.

Devido aos limites deste artigo, optou-se por abordar um dos elementos indicados como expressão da democratização: o acesso à informação como requisito para uma gestão democrática.

Frações de alguns depoimentos dos entrevistados serão apresentadas a seguir, visando ilustrar e socializar parte das reflexões por eles proporcionadas. $\mathrm{O}$ acesso dos usuários às informações - e ao conhecimento, de forma mais abrangente - foi entendido como condição para que estes consigam acessar os próprios direitos sociais:

A gente vê que tem muitas pessoas que estão carentes de informação, que não vão atrás, não porque não querem: é porque nem têm informação de como buscar essa informação (Dirigente de Entidade 1).

A falta de informação é mais um mecanismo de opressão porque pode desviar as pessoas dos caminhos de acesso a seus direitos.

Se o usuário não tem informação, às vezes ele se vê precisando de recurso para pagar um advogado para lutar, para conseguir o seu direito. E devido à sua situação financeira, ele às vezes deixa de conquistar direitos, porque não tem conhecimentos e não tem recursos para pagar um advogado; então ele deixa o direito de lado (Dirigente de Entidade 1). tilha. Ocorre que a partilha não acontece se você não tiver divisão de saberes, partilha de conhecimento (Gestora).

Nota-se que esta gestora demonstra ter muita clareza sobre a dualidade do conhecimento, sobre o risco de manipulação, mas também sobre seu caráter emancipatório:
Por outro lado, o conhecimento sempre foi uma arma importante, a favor e contra. Você pode informar as pessoas pela sua cartilha, se quiser. Quer dizer, você pode formar sem garantir autonomia de pensamen- to, sem criticidade suficiente para opinar (Gestora).

Seguindo esta perspectiva, a gestora afirma que a democratização da gestão "é uma ação mais política que técnica, porque você pode criar espaços técnicos de fala (sic), porém pode não conseguir espaços políticos de decisão." Verifica-se que os instrumentais administrativos não são descartados; pelo contrário, o que se enaltece é a dimensão política da gestão, como já discutia Nogueira (2004, p. 11-12):

Por se dispor a dirigir, coordenar e impulsionar a
formação ampliada de decisões, a gestão democrá-
tica opera em um terreno que não se esgota no
administrativo, no manuseio de sistemas e recur-
sos, mas se abre para o universo organizacional
como um todo. Ela é essencialmente dialógica, e
transcorre em ambientes éticos e políticos povoa-
dos de pessoas, desejos e interesses que não po-
dem ser simplesmente 'gerenciados'.

Tendo em vista a importância atribuída à participação no processo de gestão, outro eixo selecionado para avaliar a implantação da gestão democrática em Londrina foi a ampliação dos espaços participativos.

É preciso deixar explícito que a democratização almejada não se limita e nem se aplica exclusivamente aos organismos estatais incumbidos da execução da política de assistência social. A democratização vem sendo delineada aqui como uma modalidade de operar a política pública de assistência social, tendo por base o sistema des centralizado e participativo preconizado pela LOAS.

Outra característica apontada pelo Conselheiro 2 (que ocupou o cargo de vice-presidente no período analisado) sobre o caráter democrático da gestão foi a autonomia: 
Eu acho que a primeira forma de democratização, um grande avanço, foi o grande respeito do poder público para com o Conselho Municipal de Assistência. Respeito em que sentido? Nas deliberações, nas determinações, nas orientações às entidades, na administração do Fundo, na fiscalização (Conselheiro 2).

Evidencia-se, portanto, que a democratização precisa ser incorporada por todo o sistema que compõe a política de assistência social: supõe que a democratização não pode ser compreendida como uma norma, que é imposta, e sim como um valor a ser incorporado no cotidiano da gestão.

\section{Considerações finais}

No campo da assistência social, assim como no das políticas sociais em geral, há de se ter em conta que

O fortalecimento de suas instituições, como também a democratização das relações sociais, depende da atuação do Estado a fim de assegurar condições para o exercício da cidadania, o que envolve, principalmente, efetivação de direitos fundamentais (BENTO, 2003, p. 179-180).

As opiniões dos protagonistas da experiência municipal examinada guardam, a nosso ver, uma intrínseca complementaridade: democratizar a gestão da política de assistência social é possibilitar acesso à informação como condição de acesso aos próprios direitos socioassistenciais. Viabilizar a democratização é compartilhar com todos os envolvidos - especialmente com os usuários - as decisões acerca dos rumos que esta política deve tomar para consolidarse como pública e para contribuir com a própria história de democratização da nossa sociedade. Entendendo que, no caso brasileiro, "a incorporação dos princípios democráticos pela própria sociedade [é] um processo que certamente ainda não chegou ao seu final" (AVRITZER, 1996, p. 146).

\section{Referências}

AVRITZER, L. A moralidade da democracia: ensaios em teoria habermasiana e teoria democrática. São Paulo: Perspectiva, 1996.

Cultura política, atores sociais e democratização: uma crítica às teorias da transição para a democracia. Revista Brasileira de Ciências Sociais, São Paulo, v.10, n. 28, p.109-122, jun.1995.

BENTO, L. V. Governança e governabilidade na reforma do Estado: entre eficiência e democratização. Barueri: Manole, 2003.
BRASIL. Presidência da República. Legislação. Disponível em: $\langle$ http://www.presidencia.gov.br/legislacao $>$. Acesso em: 26 fev. 2007.

CHAUÍ, M. Marilena Chauí denuncia autoritarismo da república brasileira e propõe "proclamação democrática". Artigo capturado no site disponível em: < $\underline{\text { htp:// }}$ virtualbooks.terra.com.br/>. Acesso em: 4 set. 2004.

COUTINHO, C. N. Contra a corrente: ensaios sobre democracia e socialismo. São Paulo: Cortez, 2000.

DOWBOR, L. Tecnologias do conhecimento: os desafios da educação. Petrópolis: Vozes, 2001. (Coleção Temas Sociais).

NOGUEIRA, M. A. As possibilidades da política: idéias para a reforma democrática do Estado. São Paulo: Paz e Terra, 1998.

Um estado para a sociedade civil: temas éticos e políticos da gestão democrática. São Paulo: Cortez, 2004.

OLIVEIRA, F. Privatização do público, destituição da fala e anulação da política: o totalitarismo neoliberal. In: ; PAOLI, M. C. Os sentidos da democracia: políticas do dissenso e hegemonia global. Petrópolis: Vozes, 2000, p. 55-81.

PASTOR, M. A democratização da gestão da política de assistência social em Londrina/PR no período 20012004: a ampliação do acesso e da participação. 2006. Tese (Doutorado em Serviço Social) - Pontifícia Universidade Católica de São Paulo, São Paulo, 2006.

RAICHELIS, R. Esfera pública e conselhos de assistência social: caminhos da construção democrática. São Paulo: Cortez, 1998.

YAZBEK, M. C. Terceiro setor e a despolitização da questão social. Revista Inscrita, CFESS: Rio de Janeiro, v. 6, p. 13$19,2000$.

\section{Márcia Pastor}

Doutora em Serviço Social pela Pontifícia Universidade Católica de São Paulo

Professora do Departamento de Serviço Social da Universidade Estadual de Londrina (UEL)

UEL - Centro de Estudos Sociais Aplicados/Departamento de Serviço Social

Campus Universitário

Caixa Postal 6001

Londrina - Paraná

CEP 86.051-990 